\title{
СКАНИРУЮЩАЯ ЗОНДОВАЯ МИКРОСКОПИЯ В ИССЛЕДОВАНИЯХ ТОНКИХ ПЛЕНОК
} \section{SCANNING PROBE MICROSCOPY IN THIN FILM STUDIES}

\author{
И.В.Яминский', 2,3 д.ф.-м.н., проф., генеральный директор Центра перспективных технологий, директор \\ Энергоэффективных технологий (ORCID: 0000-0001-8731-3947), А.И.Ахметова \\ А.Н.Белозерского МГУ, ведущий специалист Центра перспективных технологий и Энергоэффективных \\ технологий (ORCID: 0000-0001-6363-8202), Г.Б.Мешков', к.ф.-м.н., ст. науч. сотр., (ORCID: 0000-0003-3930-3730) / \\ yaminsky@nanoscopy.ru \\ I.V.Yaminsky', 2,3, Doctor of Sc. (Physics and Mathematics), Prof., Director of Advanced Technologies Center, Director \\ of Energy Efficient Technologies, A.I.Akhmetoval, 2,3, Engineer of A.N. Belozersky Institute of Physico-Chemical Biology, \\ Leading Specialist of Advanced Technologies Center and of Energy Efficient Technologies, G.B.Meshkov', Cand. of Sc. \\ (Physics and Mathematics), Senior Researcher
}

DOI: $10.22184 / 1993-8578.2019 .12 .2 .128 .130$

Получено: 22.03.2019 г.

В рамках российско-иранского проекта "Инициация локальных химических реакций в осажденных тонких пленках с использованием сканирующей зондовой микроскопии" продолжены исследования с помощью сканирующей зондовой и капиллярной микроскопии по созданию многопараметрической литографии. Получены оригинальные результаты по контролируемой модификации поверхности, которая достигается за счет использования многоканальных капилляров. Точность капиллярной нанолитографии находится на уровне единиц нанометров.

As a part of the Russian-Iranian project "Initiation of local chemical reactions in deposited thin films using scanning probe microscopy", the investigations were continued with the use of scanning probe and capillary microscopy to create the multi-parametric lithography. Original results were obtained on controlled surface modification, which is achieved through the fabrication of multichannel capillaries. Accuracy of a capillary nanolithography corresponds to the level of units of nanometers.

D рамках выполнения проекта по исследованию химических реакций в тонких пленках нами проведены измерения в режиме капиллярной микроскопии в сканирующем зондовом микроскопе ФемтоСкан [1]. В данной работе мы используем двухканальные капилляры, в которых один канал (транспортный) используется для подачи реагентов, а второй (сигнальный) - для позиционирования капилляра над поверхностью образца за счет измерения ионного тока. В работе используются свежеприготовленные на установке P-1000 Pipette Puller капилляры из боросиликатного стекла. Сигнальный канал заполняется $1 \mathrm{M}$ раствором хлорида натрия. Величина ионного тока варьируется в диапазоне 0,2-1 нА при приложенной между хлорсеребряными электродами разности потенциалов в 200 мВ. Для осуществления нанолитографии транспортный канал капилляра заполняется раствором, содержащим наночастицы коллоидного золота. Скорость подачи наночастиц золота управляется электрическим потенциалом, приложенным к электроду в транспортном канале. По данным просвечивающей электронной микроскопии (LEO 912 AB), характерный диаметр наночастиц золота составляет около 20 нм (рис.1). Эти данные также подтверждены методом лазерного рассеяния одиночных наночастиц [2]. 


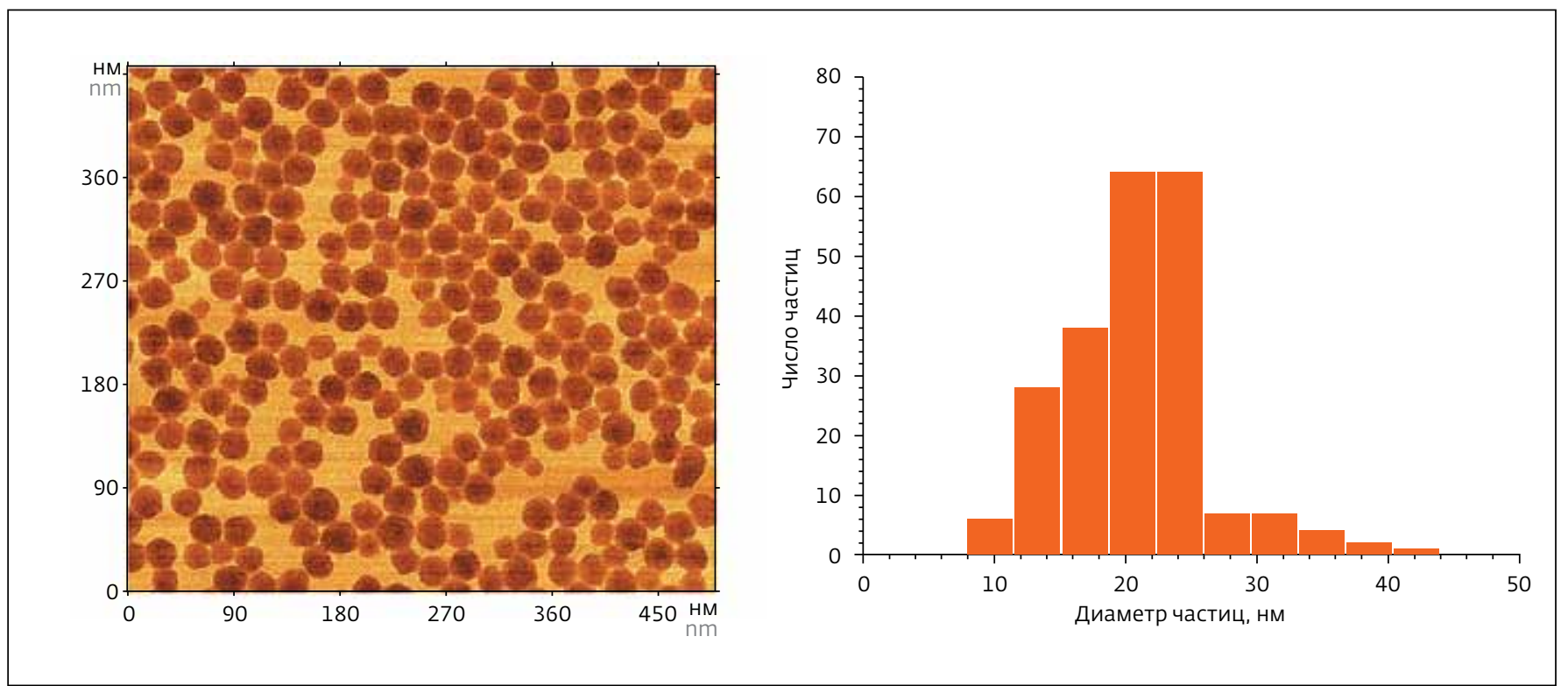

Pис.1. Слева - изображение наночастиц золота в ПЭМ. Справа - распределение частиц по диаметру Fig.1. The image of golden nanoparticles obtained by TEM (left) and distribution of the particles by the diameter (right)

Проведены исследования топографии поверхности дисульфида вольфрама (рис.2) и трисульфида титана (рис.3), нанесенных на оксид кремния. Образцы были предоставлены Технологическим университетом имени Шарифа. На полученных изображениях отчетливо видна слоистая структура этих элементов. Для обработки результатов использовалось программное обеспечение "ФемтоСкан Онлайн" [3].
Для проведения экспериментов была разработана бокс-система, которая позволяет регулировать параметры среды в процессе измерений. В частности, при создании литографии по методу локального анодного окисления осуществлялся контроль влажности воздуха. Процент содержания воды в воздухе определяет пороговое электрическое напряжение,

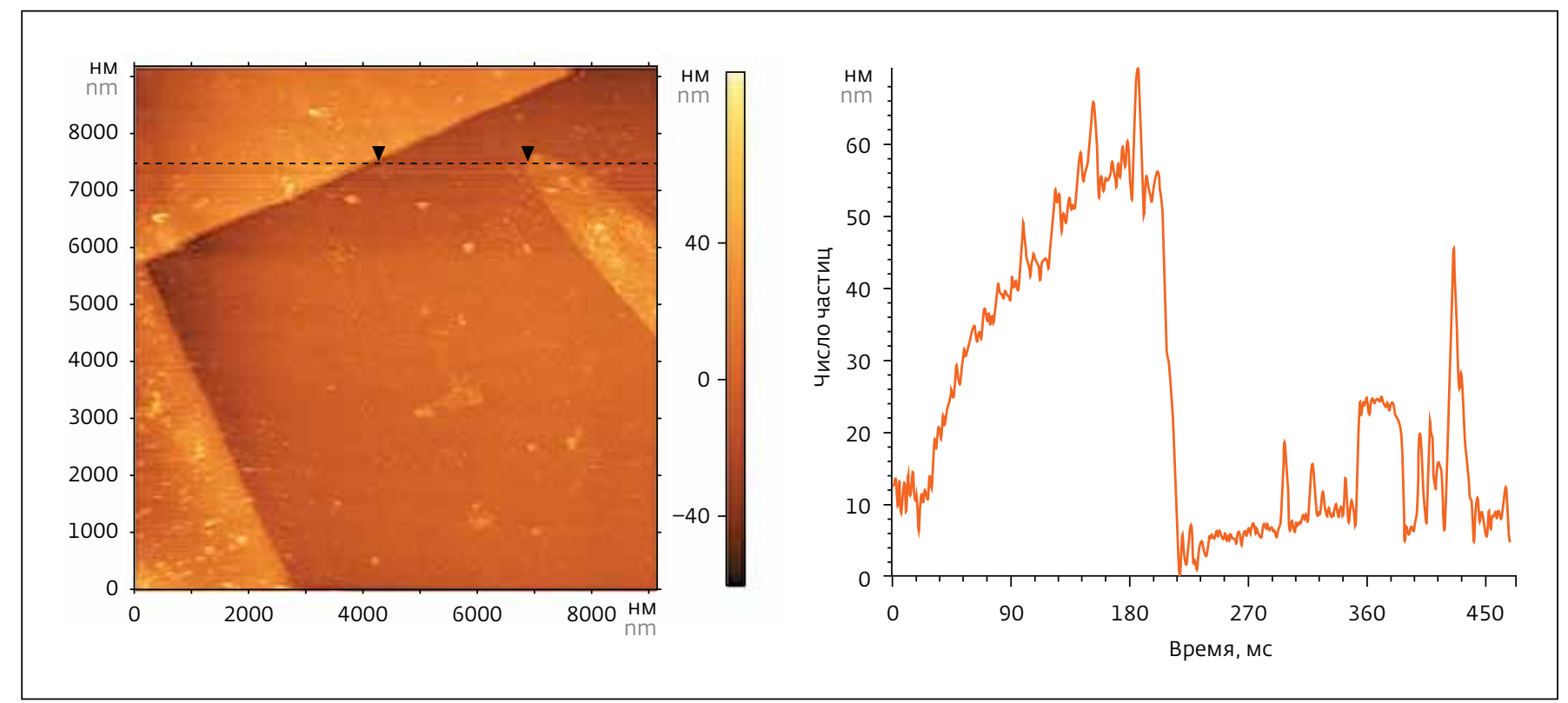

Рис. 2. Изображение $\mathrm{WS}_{2}$ на поверхности $\mathrm{SiO}_{2}$ (слева) и профиля вдоль выбранной пунктирной пинии (справа). Контактный режим атомно-силовой микроскопии

Fig.2. The image of $\mathrm{WS}_{2}$ on the $\mathrm{SiO}_{2}$ surface (left) and profile along the dashed line (right). AFM contact mode 

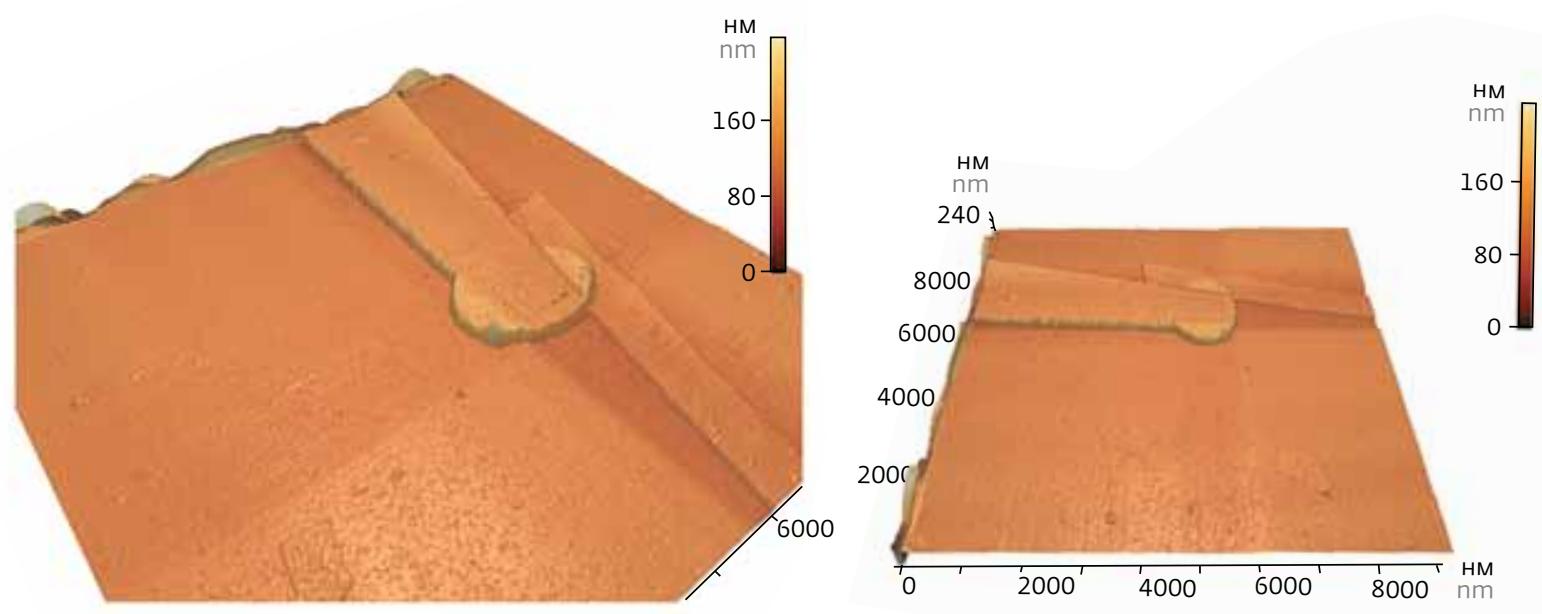

Puс.3. Изображение $\mathrm{TiS}_{3}$. Контактный режим атомно-силовой микроскопии

Fig.3. The image of TiS 3 surface. AFM contact mode

при котором происходит локальное окисление материалов [4]. Бокс-система выполнена в виде герметичной емкости из пенопласта, внутри которой расположен сканирующий зондовый микроскоп. В бокс-системе осуществляется мониторинг температуры и влажности. Также имеется возможность контролируемой подачи газа (например, сухого азота) во внутренний объем бокс-системы. Бокс-система позволяет провести оценку влияния параметров окружающей среды на характер протекания поверхностных локальных реакций.

В настоящей работе достигнуто выполнение основных задач с получением практически важных результатов:

- разработана многопараметрическая литография с помощью нанокапилляров с несколькими каналами . Многопараметрическая литография позволяет реализовать контролируемую модификацию поверхности материалов за счет локальной доставки реагентов и материалов (наночастиц) в заданную область с нанометровой точностью;

- осуществлена дозированная подача жидких сред и реагентов через дополнительные каналы нанокапилляров. При управлении скорости подачи реагентов определенной концентрации осуществлена локальная доставка химических реагентов в область нанометровых размеров, в пределах которой проходила химическая реакция;
- сконструирована бокс-система для задания параметров газовой среды в контролируемых условиях (состав газовой атмосферы, температура, влажность, скорость потока, уровень освещенности). Бокс-система создана для определения влияния параметров окружающей среды на характер протекания поверхностных локальных реакций;

- разработаны физико-химические принципы инициации локальных химических реакций с использованием нанокапилляров для подачи в область нанометрового размера требуемых реагентов.

Исследование выполнено при финансовой поддержке РФФИ в рамках научного проекта 17-52-560001.

\section{ЛИТЕPATУPA / REFERENCE}

1. Yaminsky I., Akhmetova A., Meshkov G., Salehi F. Combined capillary and probe microscopy. Nanoindustry, 1 (80): 44-48, 20.

2. Gaskarov A., Yaminsky I. Microscopy in clinical diagnostics. Detection of particles of nanometer size // Nanoindustry. 2013. № 3. P. 50-55.

3. Yaminsky I.V., Akhmetova A.I., Meshkov G.B. FemtoScan Online Software and Visualization of Nano-Objects in High-Resolution Microscopy // Nanoindustry. 2018. Vol. 10. No 6 (85). P. 414416.

4. Akhmetova A.I., Yaminsky I.V., Farshad S. Nanolithography using scanning probe microscopy in natural environments. NBICS-NT, 3: 71-77, 2018. 